\title{
OPEN Enhancing recovery of bioactive compounds from Cosmos caudatus leaves via ultrasonic extraction
}

\begin{abstract}
Norliza Abdul Latiff1,3凶, Pei Ying Ong ${ }^{3}$, Siti Nor Azlina Abd Rashid ${ }^{3}$, Luqman Chuah Abdullah ${ }^{1 凶}$, Nor Amaiza Mohd Amin ${ }^{2}$ \& Noor Akhmazillah Mohd Fauzi ${ }^{4}$

Cosmos caudatus ( $C$. caudatus) is a medicinal plant that is high in bioactive compounds such as phenolics. In this study, an ultrasound extraction method was used to optimise the extraction of bioactive compounds from C. caudatus leaves. Response surface methodology (RSM) based on a BoxBehnken design (BBD) was applied to obtain the optimum extraction parameters which is solid-liquid ratio $(10-30 \mathrm{~g} / \mathrm{mL})$, particle size $(180-850 \mu \mathrm{m})$ and extraction time (20-30 $\mathrm{min})$ for maximal quercitrin and total phenolic content (TPC) yields. Analysis of antimicrobial activity was performed against two human pathogenic microbes: Staphylococcus aureus (S. aureus) and Escherichia coli (E. coli) by the agar well diffusion method. The optimal ultrasonic extraction condition was as follow: solvent-liquid ratio of 1:28 ( $\mathrm{g} / \mathrm{mL})$, particle size of $485 \mu \mathrm{m}$, and duration of $30 \mathrm{~min}$, respectively. Remarkably, extraction using ultrasonic method had recovered more bioactive content and antioxidant activity than the Soxhlet method. The extract also exhibited good antimicrobial activities. Due to the above findings, the ultrasonic extraction was found to be suitable to improve recovery extraction of quercitrin and TPC from C. caudatus leaves. It also opens the possibility that the plant extract can be used for functional food and antimicrobial agents in various applications.
\end{abstract}

Cosmos caudatus (C. caudatus) is a small plant belonging to the Asteraceae family ${ }^{1}$. In Southeast Asia countries like Malaysia and Indonesia, the plant is usually consumed as food and used in traditional folk medicine ${ }^{1,2}$. The leaves and shoots can be eaten raw as a side dish with meals as well as for other culinary purposes ${ }^{2,3}$. Previous work has been done on the plant extraction mostly on the leaves which reported various pharmacological properties such as anti-bacterial, anti-inflammatory, bone-protective agent, and anti-diabetic ${ }^{2,4-9}$. Some studies have demonstrated that the extract has more powerful antioxidant properties contrasted to some tropical fruits, herbs, and vegetables ${ }^{10,11}$. In addition, the plant is also rich in vitamins (B1, B2, C and $\beta$-carotene), minerals (potassium, calcium, magnesium, phosphorus, iron, zinc, sodium and copper) and is low in calories ${ }^{1,12}$.

Phytochemical studies on this plant described various bioactive compounds such as quercetin derivatives (quercetin-3-O-rhamnoside, quercetin-3-rutinoside, quercetin glucoside), phenolics, ascorbic acid, proanthocyanins, and catechin ${ }^{13-16}$. Various researchers reported quercetin-3-O-rhamnoside or quercitrin as the major compound in the plant extract ${ }^{9,14,16}$. Previous studies also demonstrated that quercitrin possessed tremendous bioactivities such as antioxidant, antibacterial, osteoblast protection, and allergic prevention ${ }^{17-20}$. Thus, it is important to investigate the extraction and separation of bioactive compounds from the plant materials. To our best knowledge, research focusing on the extraction of specific bioactive compounds from the herb has not been yet reported. Therefore, in considering the beneficial prospects of the plant leaf extract as a source of antioxidant compounds from quercitrin, an efficient extraction method and process should be developed and proposed.

It is desirable to develop a strategy plant's extraction method which can reduce the time and production costs yet applies the green concept with low energy and eco-friendly. Various modification methods with either ultrasonic, microwave, ultra-high pressure or supercritical fluid extractions assistance can be applied ${ }^{21,22}$. Ultrasound-assisted extraction, either using the ultrasonic bath or ultrasonic probe devices, could be the alternative and promising green extraction technology among the established methods ${ }^{22-24}$. It provides a faster, simpler operation method, has high reproducibility, and it is suitable for thermo-labile compound $\mathrm{s}^{25-27}$. The extraction

${ }^{1}$ Department of Chemical and Environmental Engineering, Faculty of Engineering, Universiti Putra Malaysia, 43400 Serdang, Selangor, Malaysia. '2Department of Process and Food Engineering, Faculty of Engineering, Universiti Putra Malaysia, 43400 Serdang, Selangor, Malaysia. ${ }^{3}$ Innovation Centre in Agritechnology, Universiti Teknologi Malaysia, 84600 Muar, Johor, Malaysia. ${ }^{4}$ Department of Chemical Engineering Technology, Faculty of Engineering Technology, Universiti Tun Hussein Onn Malaysia, Pagoh Higher Education Hub, 84600 Muar, Johor, Malaysia. ${ }^{\bowtie}$ email: norlizaabdlatiff@utm.my; chuah@upm.edu.my 
efficiency can be increased by the acoustic cavitation in the solvent which leads to the disruption or breakdown of plant cell walls. This mechanism accelerates molecules movement and increases the mass transfer process in contact with solid material during the extraction process ${ }^{28,29}$. The parameters of ultrasonic extraction efficiency can be affected by ultrasonic irradiation time, temperature, frequency, the ratio between solvent to solid ratio, and solvent types ${ }^{30,31}$. Similarly, the applied extraction parameters should be carried out under optimal conditions to produce a high yield recovery of the targeted extraction. This can be achieved by carrying out a statistical design based on response surface methodology (RSM) ${ }^{27}$.

Studies conducted elsewhere have revealed various extraction methods for C. caudatus $^{32-35}$, however, there are no reports about the recovery yield of the bioactive compound from C. caudatus leaves extract. Therefore, the present study utilised ultrasonic extraction to extract the bioactive compound and the parameter of extractions were then optimised using response surface methodology. The extract obtained under optimal ultrasonic extraction conditions were then compared to the Soxhlet extraction method in terms of yields and effectiveness. Furthermore, an analysis of antimicrobial activity was performed to evaluate the potential of plant extract as an antimicrobial agent against the following two human pathogens: Staphylococcus aureus (S. aureus) and Escherichia coli (E. coli).

\section{Materials and methods}

Plants sample collection and preparation of Cosmos caudatus extract. Cosmos caudatus (C. caudatus) was collected from the university's research farm of Universiti Teknologi Malaysia, located at Pagoh, Johor $(2.15582,102.73446)$. The date of collection was in April 2019 and October 2019. The plant was authenticated by the botanist (Dr Mohd Firdaus Ismail), Institute of Bioscience, Universiti Putra Malaysia. After analysed, the plant specimens were deposited in the herbarium laboratory of Universiti Teknologi Malaysia, Pagoh. The fresh leaf parts were dried at $40{ }^{\circ} \mathrm{C}$ for $4 \mathrm{~h}$ in a laboratory oven dryer ${ }^{12}$. The dried leaves were subsequently ground into a powder and sieved (Wstyler, Mentor, OH, USA). The samples obtained were kept and sealed in an air-tight container and maintained at $-25^{\circ} \mathrm{C}$ until further used.

Chemicals and reagents. Quercitrin and gallic acid (3,4,5-trihydroxy benzoic acid, 99\%) and Folin-Ciocalteu phenol reagent, $\mathrm{Na}_{2} \mathrm{CO}_{3}$, formic acid (HPLC grade), 1-diphenyl-2-picryl-hydrazyl (DPPH), and Streptomycin was procured from Sigma Aldrich (Steinheim, Germany). Ethanol (reagent grade) was purchased from Across Organics (Leicestershire, England). Methanol (HPLC grade) and Acetonitrile (HPLC grade) were obtained from Daejung Company, Ltd. (Busan, South-Korea).

Ultrasonic extraction. Ultrasonic extraction was carried out in an ultrasonic bath device (i.e., WiseD; Daihan Scientific, Ltd Co, South-Korea) at a constant frequency of $40 \mathrm{kHz}$ with $175 \mathrm{~W}$ of power. The ultrasonic time, temperature, and power intensity were controlled from the instrument panel. The dried and grounded samples were immersed into a $100 \mathrm{~mL}$ glass beaker containing a solvent $(80 \% \mathrm{v} / \mathrm{v} \text { ethanol })^{13}$. The beaker was put in the ultrasonic bath and the temperature was maintained at $50{ }^{\circ} \mathrm{C}$. After completion of the extraction process, the samples were filtered into a vacuum pump and the clear supernatant was transferred into a concentrator centrifuge tube (Concentrator plus, Hamburg, Germany) and concentrated until dryness. Afterwards, the crude extract was refrigerated at $-25^{\circ} \mathrm{C}$ to minimise the degradation of the bioactive compounds caused by oxidation, prior to subsequent analysis.

Soxhlet extraction. Extraction was performed using the Soxhlet apparatus. The dried and grounder leaf sample was placed in a thimble chamber and inserted into the thimble holder condenser. It was attached to a $250 \mathrm{~mL}$ distillation flask. The sample $(1 \mathrm{~g})$ and $80 \%$ ethanol $(200 \mathrm{~mL})$ were used for the extraction process. The extraction was maintained for $5 \mathrm{~h}$ at $80^{\circ} \mathrm{C}$. After completing the extraction, the residue was filtered in a vacuum pump and concentrated until dryness using a solvent centrifugal concentrator (Concentrator plus, Hamburg, Germany). The samples were kept refrigerated at $-25^{\circ} \mathrm{C}$ before analysis.

High-performance liquid chromatography analysis (HPLC). The chromatographic analysis of quercitrin from C. caudatus leaf extract was done using a 1290 Infinity HPLC coupled with a diode array detector system (HPLC-DAD) (Agilent Technologies, Santa Clara, CA, USA). A reverse-phase column (Inertsil ODS, $5 \mu \mathrm{m}, 250 \mathrm{~mm} \times 4.6 \mathrm{~mm}$ I.D.) was used for separation of the compound. The analysis of quercitrin was following Sharifuldin et al. ${ }^{14}$ with some adjustments. The injection volume was $10 \mu \mathrm{L}$. The elution set were $0.3 \%$ formic acid in water (A) and 100\% acetonitrile (B) with the following sequence of A distributions as follows: $0 \mathrm{~min}-80 \%$, $10 \mathrm{~min}-50 \%, 11 \mathrm{~min}-0 \%, 14 \mathrm{~min}-80 \%$. The separation was achieved at a flow rate of $0.5 \mathrm{~mL} / \mathrm{min}$ for a $14 \mathrm{~min}$ run time. The detection wavelength of quercitrin was achieved at $260 \mathrm{~nm}$ and the wavelength was integrated by OpenLab software (Agilent Technologies, Santa Clara, CA, USA). The quercitrin content was calculated using a linear regression equation that was obtained from the standard calibration curve of quercitrin and expressed as $\mathrm{mg}$ quercitrin per $\mathrm{g}$ of dry weight extract $(\mathrm{mg} / \mathrm{g} \mathrm{dw})$. Before the injection, all samples were filtered using a nylon membrane $0.45 \mu \mathrm{m}$. The experiments were conducted in triplicate.

Total phenolic content analysis by UV-spectrophotometric. The total phenolic content (TPC) of the leaf extract was analysed using the UV-spectrophotometric method by Safdar et al. ${ }^{36}$ with modifications. Briefly, a set of $40 \mu \mathrm{L}$ extracts were added into a 96-well plate, followed by $100 \mu \mathrm{L}$ Folin-Ciocalteau's reagent (tenfold diluted). After $5 \mathrm{~min}$ of reaction, $80 \mu \mathrm{L}$ of $\mathrm{Na}_{2} \mathrm{CO}_{3}(7.5 \mathrm{~g} / 100 \mathrm{~mL})$ was added to the sample solutions. The samples were shaken and incubated at ambient temperature $\left(26^{\circ} \mathrm{C}\right)$ to develop a blue colour. After $90 \mathrm{~min}$, 


\begin{tabular}{|l|l|l|l|}
\hline Factors & \multicolumn{3}{|l|}{ Independent variables } \\
\hline Levels & $\mathbf{X}_{\mathbf{1}}(\mathrm{g} / \mathbf{m L})$ & $\mathbf{X}_{2}(\boldsymbol{\mu m})$ & $\mathbf{X}_{\mathbf{3}}(\mathbf{m i n})$ \\
\hline-1 & 10 & 180 & 20 \\
\hline 0 & 20 & 515 & 25 \\
\hline+1 & 30 & 850 & 30 \\
\hline
\end{tabular}

Table 1. The selected independent variables and coded values. Parameters: $\mathrm{X}_{1}=$ solvent to solid ratio, $\mathrm{X}_{2}=$ particle size, and $\mathrm{X}_{3}=$ time.

the samples were measured at an absorbance at $765 \mathrm{~nm}$ using an ELISA microplate reader (VersaMax, Molecular Devices, LLC, USA). The TPC was expressed as mg gallic acid equivalent per $\mathrm{g}$ of dry weight extract (mg GAE/g $\mathrm{dw})$. All experiments were conducted in triplicate.

Antioxidant analysis by UV-spectrophotometric. The antioxidant assay was determined using free radical scavenging method as referred to Latiff et al. ${ }^{37}$. Free radical agent, namely 1,1-diphenyl-2-picryl-hydrazyl (DPPH), was prepared in $100 \% \mathrm{CH}_{3} \mathrm{OH}$ (reagent grade) with a concentration of $0.1 \mathrm{mM}$. A serial dilution of samples were inserted into a 96-well plate. The samples were mixed with $10 \mu \mathrm{L} \mathrm{DPPH}$ reagent. The mixtures were shaken in a platform shaker (Polymox 1040, Heidolph Instruments GmBH \& CO. Schwabach, Germany) and allowed to stand at room temperature $\left(26^{\circ} \mathrm{C}\right)$, with minimal light exposure. After 30 min reaction, the samples absorbance was recorded at $515 \mathrm{~nm}$ using an ELISA microplate reader (VersaMax, Molecular Devices, LLC, USA). The ascorbic acid was used as a standard and DPPH (without extract) as a control sample was also prepared and similarly analysed. All experiments were conducted in triplicates. The reduction rate of DPPH was calculated with the following Eq. (1).

$$
\text { \%Inhibition }=\frac{\mathrm{A}_{\mathrm{s}}-\mathrm{A}_{\mathrm{s}}}{\mathrm{A}_{\mathrm{c}}} \times 100
$$

where, $A_{c}$ is the absorbance of the control, and $A_{s}$ is the absorbance of extract.

Antimicrobial analysis. Two clinical human pathogenic bacteria; Staphylococcus aureus (S. aureus) and Escherichia coli (E. coli) were used to determine the antimicrobial potential using the agar well diffusion method $^{38}$. The nutrient agar was inoculated with bacteria and treated with the $50 \mu \mathrm{L}$ plant extract $(40 \mathrm{mg} / \mathrm{mL})$. The same assay was also performed with standard compound of quercitrin $(1 \mathrm{mg} / \mathrm{mL})$. After the incubation period of $24 \mathrm{~h}$ under a controlled temperature $\left(30^{\circ} \mathrm{C}\right)$, the diameter of the inhibition zone was measured. Standard antibiotic of Streptomycin $(10 \mathrm{mg} / \mathrm{mL})$ was used as control in this study.

Optimization of ultrasonic extraction by Box-Behnken experimental design. Prior to the study, a single-factor experiment was performed on four extraction variables [solid-liquid ratio (SLR), particle size, amplitude, and time] and its effect on the yield of quercitrin and TPC was analysed. The study was performed over 19 tests (with three replicates for each test) to determine its effect and range (see Supplementary Information). Based on the results of the single-factor experiments, parameters of SLR, particle size, and time were selected as the important parameters that significantly affect the quercitrin and TPC yields. These parameters have also been taken as the important for quercitrin and phenolic extraction in ultrasonic and other extraction process $^{39,40}$. Table 1 showed the parameters used in the optimization study. Amplitude level was set constant at $40 \%$ in this study. A three-level Box-Behnken design (BBD) was performed to investigate and optimise the effect of the selected extraction variables. The mean values from the experimental works were fitted in a second-order polynomial equation to predict the responses using the Eq. (2).

$$
Y=\beta_{0} \sum_{\mathrm{i}=1}^{\mathrm{k}} \beta_{i} x_{i}+\sum_{\mathrm{i}=1}^{\mathrm{k}} \beta_{i i} x^{2}{ }_{i}+\sum_{1 \leq \mathrm{i} \leq \mathrm{j}}^{\mathrm{k}} \beta_{i j} x_{i} x_{j}
$$

where, $\mathrm{Y}$ represents the predicted response (quercitrin and TPC), $\mathrm{k}$ stands for the number of factors determined $(\mathrm{k}=3)$ in this study, $\beta_{0}, \beta_{i}, \beta_{i i}, \beta_{i j}$ represent the coefficients term as linear, quadratic, and interactive, respectively, $x_{i}, x_{i i}$, and $x_{i j}$ are the coded independent factors ${ }^{22,41}$.

The statistical data ( $p$-value) among the independent and coefficient terms was evaluated by the analysis of variance (ANOVA). The data was generated using Minitab version 16 (Coventry, London). The result with small $p$-value $(p \leq 0.05)$ and larger F-value indicated that the model term was significant ${ }^{42,43}$. Contour and surface plots were also generated to visualize the interaction among the independent variables. The validity of the optimum conditions was checked through desirability values of the response ( 0 to 1$)$, which value close to 1 shows the more optimal conditions ${ }^{44,45}$.

Ethical statement. Research carried out as per guidelines and recommendations of "Malaysian Herbal Monographs 2015", published by the Ministry of Agriculture and Food Industries of Malaysia. No permit or permission is required for collection of seeds and plants. 


\begin{tabular}{|l|l|l|l|l|l|l|l|}
\hline & & & & \multicolumn{2}{l|}{ Quercitrin $(\mathbf{m g} / \mathbf{g} \mathbf{d w})$} & \multicolumn{2}{l|}{ TPC $(\mathbf{m g}$ GAE/g dw) } \\
\cline { 8 - 10 } Run no. & $\mathbf{X}_{1}$ & $\mathbf{X}_{2}$ & $\mathbf{X}_{3}$ & Experimental & Predicted & Experimental & Predicted \\
\hline 1 & 30 & 515 & 20 & 25.85 & 26.09 & 188.28 & 188.78 \\
\hline 2 & 10 & 515 & 30 & 49.14 & 49.41 & 125.42 & 125.36 \\
\hline 3 & 30 & 180 & 25 & 22.08 & 22.94 & 178.72 & 177.65 \\
\hline 4 & 10 & 515 & 20 & 54.11 & 55.45 & 126.39 & 127.51 \\
\hline 5 & 10 & 180 & 25 & 40.31 & 40.07 & 119.75 & 118.05 \\
\hline 6 & 30 & 850 & 25 & 20.81 & 21.05 & 180.96 & 182.65 \\
\hline 7 & 20 & 180 & 30 & 43.87 & 44.35 & 137.60 & 139.79 \\
\hline 8 & 20 & 850 & 20 & 40.15 & 39.67 & 149.12 & 146.93 \\
\hline 9 & 20 & 515 & 25 & 45.92 & 45.39 & 148.56 & 148.65 \\
\hline 10 & 20 & 515 & 25 & 45.58 & 45.39 & 146.56 & 148.65 \\
\hline 11 & 20 & 850 & 30 & 41.90 & 43.07 & 136.20 & 135.63 \\
\hline 12 & 10 & 850 & 25 & 42.50 & 41.58 & 120.30 & 121.37 \\
\hline 13 & 30 & 515 & 30 & 42.46 & 41.11 & 186.09 & 184.97 \\
\hline 14 & 20 & 180 & 20 & 38.98 & 38.71 & 133.88 & 134.45 \\
\hline 15 & 20 & 515 & 25 & 44.67 & 45.39 & 150.82 & 148.65 \\
\hline
\end{tabular}

Table 2. BBD model fitness for optimum yield of quercitrin and TPC from C. caudatus leaves. $\mathrm{X}_{1}=$ solvent to solid ratio, $\mathrm{X}_{2}=$ particle size, and $\mathrm{X}_{3}=$ time.

\begin{tabular}{|c|c|c|c|c|}
\hline & \multicolumn{2}{|l|}{$Y_{1}$} & \multicolumn{2}{|l|}{$\mathrm{Y}_{2}$} \\
\hline & Coefficient & p-value & Coefficient & $p$-value \\
\hline$\beta_{0}$ & 151.264 & & 41.933 & \\
\hline Linear & & $0.000^{*}$ & & $0.000^{*}$ \\
\hline $\mathrm{X}_{1}$ & -0.964 & $0.000^{*}$ & -0.582 & $0.000^{*}$ \\
\hline $\mathrm{X}_{2}$ & 0.085 & 0.852 & 0.140 & 0.063 \\
\hline $\mathrm{X}_{3}$ & -9.135 & $0.005^{*}$ & 3.871 & 0.148 \\
\hline Quadratic & & $0.000^{*}$ & & $0.001^{\star}$ \\
\hline $\mathrm{X}_{1}^{2}$ & -0.062 & $0.000^{*}$ & 0.094 & $0.001^{\star}$ \\
\hline $\mathrm{X}_{2}^{2}$ & -6.932 & $0.000^{*}$ & $-7.204 \times 10-5$ & $0.001^{*}$ \\
\hline $\mathrm{X}_{3}^{2}$ & 0.153 & $0.003^{*}$ & -0.054 & 0.337 \\
\hline Interaction & & $0.003^{*}$ & & 0.089 \\
\hline $\mathrm{X}_{1} \mathrm{X}_{2}$ & $-2.542 \times 10^{-4}$ & 0.263 & $1.254 \times 10-4$ & 0.747 \\
\hline $\mathrm{X}_{1} \mathrm{X}_{3}$ & 0.1053 & $0.001^{*}$ & -0.008 & 0.749 \\
\hline $\mathrm{X}_{2} \mathrm{X}_{3}$ & 3.419 & 0.435 & -0.002 & $0.020^{*}$ \\
\hline $\mathrm{R}^{2}$ & 99.30 & & 99.62 & \\
\hline Adj. $\mathrm{R}^{2}$ & 89.69 & & 95.53 & \\
\hline Pre. $\mathrm{R}^{2}$ & 98.04 & & 98.95 & \\
\hline Lack of fit & 0.135 & & 0.413 & \\
\hline
\end{tabular}

Table 3. Analysis of variance of the predicted models for quercitrin and TPC from C. caudatus leaves. Parameter values with ${ }^{\star}$ is significant term at $p \leq 0.05$.

\section{Results and discussion}

Ultrasonic extraction parameter optimisation. In this study, the BBD was performed to determine the optimal independent variables for the maximal quercitrin and TPC yields from C. caudatus leaves. An extraction model based on a second-order polynomial equation was then developed. The results obtained from the actual works and the predicted values by the second-order polynomial equation model are shown in Table 2 . The experimental values of quercitrin ranged from 20.81 to $54.11 \mathrm{mg} / \mathrm{g} \mathrm{dw}$, while the predicted values ranged from 21.05 to $55.45 \mathrm{mg} / \mathrm{g} \mathrm{dw}$. For the TPC, the experimental values ranged from 119.72 to $188.28 \mathrm{mg} \mathrm{GAE} / \mathrm{g} \mathrm{dw}$, while the predicted values ranged from 118.05 to $188.78 \mathrm{mg} \mathrm{GAE} / \mathrm{g} \mathrm{dw}$.

The ANOVA data of the predicted models is displayed in Table 3. In this study, the model was significant for the two respective responses. The presented data showed the best fit with higher R-square value $\left(\mathrm{R}^{2}\right)$ corresponding to 0.9930 for quercitrin and 0.9962 for TPC. The adjusted $\mathrm{R}^{2}$ value for quercitrin was 0.8969 and close to their $\mathrm{R}^{2}$ value. While the adjusted $\mathrm{R}^{2}$ value for TPC was 0.9953 and close to their $\mathrm{R}^{2}$ value. Both predicted $\mathrm{R}^{2}$ values were in reasonable agreement, where the difference was less than $0.2^{22}$. The lack of fit was not statistically 
significant at $\mathrm{p}>0.05$, showing a high degree of fit with the model for predicting the extraction yield ${ }^{27,46}$. The developed models were satisfactory to describe the connection between the independent and the response variables.

The positive and negative sign of the coefficient shown is related to effect of increase or decrease in its value. In the case of quercitrin, the SLR and time had the most significant effect in the linear term, both showing a negative coefficient value, while particle size showed a less significant effect with a positive coefficient sign. The quadratic term between three variables had a greater effect to influence the quercitrin yield, whereas the interactive effect was only significant with a negative sign between the SLR and extraction time. This implies that the higher yield of quercitrin could be achieved when reducing the SLR and extraction time. After considering an only significant effect, the final regression model of quercitrin was given in Eq. (3):

$$
\begin{aligned}
\mathrm{QR} \text { content }\left(Y_{1}\right)= & 151.264-0.964 \mathrm{X}_{1}-9.135 \mathrm{X}_{3}-0.062 \mathrm{X}_{1}^{2}-6.932 \times 10^{-5} \mathrm{X}_{2}^{2}+0.153 \mathrm{X}_{3}^{2} \\
& +0.105 \mathrm{X}_{1} \mathrm{X}_{3} .
\end{aligned}
$$

For the TPC, among the independent variables, only the SLR displayed a strong significant linear effect with a negative coefficient sign. The quadratic term was significant and corresponded to the SSR and particle size, except for the extraction time. The interactive effect of particle and time were significant and had a greater effect on the TPC. The negative coefficient denoted that decreasing the particle size and extraction time to a certain level could result in a higher TPC while applying a higher SLR could increase the yield. As for the final equation for prediction of TPC, after excluding the insignificant terms, the final equation was given in the following Eq. (4):

$$
\operatorname{TPC}\left(\mathrm{Y}_{2}\right)=41.933-0.582 \mathrm{X}_{1}+0.094 \mathrm{X}_{1}^{2}-7.204 \times 10^{-5} \mathrm{X}_{2}^{2}-0.002 \mathrm{X}_{2} \mathrm{X}_{3}
$$

Analysis of the contour and surface plot. The two-dimensional (2D) contour and three-dimensional (3D) surface plots are used to graphically represent the interactive effects of the studied variables to the responses ${ }^{47}$. The response plots of quercitrin content are presented in Fig. 1a-c, while Fig. 2a,b shows the response plots of TPC. Figure la,b displays the impact of particle size and time on quercitrin and TPC extraction while holding SLR at 1:20 $\mathrm{g} / \mathrm{mL}$. In decreasing the particle size from 850 to $500 \mu \mathrm{m}$ and by increasing the time 25 min shows increment yields in quercitrin and TPC. We had also examined these effects in our preliminary screening, which larger particle size of $2500 \mu \mathrm{m}$ recovered less quercitrin and TPC compared to the smaller particle below $850 \mu \mathrm{m}$ (see Supplementary Information). According to Mohd ${ }^{39}$, the maximum concentration of quercitrin from the Melastoma malabthricum leaf could be extracted with an average particle size of $450 \mu \mathrm{m}$, using an ultrasonic extraction. In general, the extraction yield improved when reducing the particle size from crushed to powdered particle $e^{39,48,49}$. When the particle size is reduced, extraction yield increases due to a higher contact surface area of the sample with the solvent. In addition, the reduction of the particle size allows for a better mass transfer process due to the reduction in the diffusion path and the enlargement of the contact surface $\operatorname{area}^{50}$. Vuong and his team ${ }^{51}$ inspected the effect of particle size $(<1 \mathrm{~mm})$ of green tea on the extraction efficiency. At the respective conditions, small particles sink to the bottom of the extraction vessel, and additional steps for the extraction are needed (e.g., separation, filtration, or centrifugation) to clear the sediment. This may reduce the extraction efficiency as the steps required cost, energy, and time ${ }^{47}$.

Figures $1 \mathrm{~b}$ and $2 \mathrm{~b}$ shows the mutual interaction of particle size and SLR on quercitrin and TPC extraction with the time set at $25 \mathrm{~min}$. For the SLR, the quercitrin yield was slightly increased with increasing SLR $(1: 10 \mathrm{~g} / \mathrm{mL}$ to $1: 20 \mathrm{~g} / \mathrm{mL})$ and reducing particle size $(850-500 \mu \mathrm{m})$. As shown in Fig. $1 \mathrm{~b}$, the maximal content of quercitrin reaches $48.07 \mathrm{mg} / \mathrm{g} \mathrm{dw}$ using SLR at $16.14 \mathrm{~g} / \mathrm{mL}$ and particle size at $543 \mu \mathrm{m}$. In Fig. $2 \mathrm{~b}$, the TPC value could be increased when SLR higher than $1: 30 \mathrm{~g} / \mathrm{mL}$ was used for the extraction $(184.74 \mathrm{mg} \mathrm{GAE} / \mathrm{g} \mathrm{dw})$. The results are consistent as reported by Ma et al..$^{40}$, Mohd ${ }^{39}$ and Chen et al. ${ }^{52}$. With the increase in SLR, viscosity of the medium solution decreases, and increases in concentration gradient leading to more solvent access into the material and producing a higher extraction yield.

The present study had examined the mutual interaction of ultrasonic extraction time and SLR on quercitrin and TPC extraction. The particle size was set constant at $515 \mu \mathrm{m}$. As displayed in Figs. $1 \mathrm{c}$ and $2 \mathrm{c}$, the extraction was favoured if a longer time was used. A longer time increase up to 30 min gradually increased both extraction yields and solute release as it promoted the extension, cell wall degradation. The increase in sonication time also caused the power and solvent temperature to increase, thereby effecting the extraction yield ${ }^{53,54}$. However, in some cases, extraction efficiency may decrease due to the prolonged sonication time as it reduces the permeability of the solvents to the cell walls due to the over-suspended impurities and affecting its mass transfer ${ }^{31,39}$. In the present study, the solvent temperature was controlled at $50{ }^{\circ} \mathrm{C}$ to avoid structural damage to the solute and to increase the quercitrin and TPC yields. Mohd ${ }^{39}$ reported ultrasonic extraction time of 15 min could be optimum for quercitrin from M. malabathricum leaves. However, the results were found to be contradicted with Zulkiply ${ }^{35}$ who observed ultrasonic extraction time of $300 \mathrm{~min}$ is the best to achieve the maximal TPC yield from C. caudatus leaves extract.

Predicted optimal extraction conditions and verification. The optimal conditions of the studied variables were determined by setting the goal at the maximum responses using the optimizer plot. The overall desirability of the regression models was achieved at 0.9508 , which is close to 1 . The predictive maximum values of quercitrin and TPC were $44.26 \mathrm{mg} / \mathrm{g} \mathrm{dw}$, and $175.64 \mathrm{mg} \mathrm{GAE} / \mathrm{g} \mathrm{dw}$, respectively under the optimised condition of SLR 1:28 $(\mathrm{g} / \mathrm{mL})$, particle size $485 \mu \mathrm{m}$, and extraction time $30 \mathrm{~min}$ (Table 4). Meanwhile, the values from the actual experimental work were recorded at $42.57 \mathrm{mg} / \mathrm{g} \mathrm{dw}$ and $169.75 \mathrm{mg} \mathrm{GAE} / \mathrm{g} \mathrm{dw}$, respectively. These measured values were consistent and close to the values predicted by the model equation. The percentage 
(a)

Contour Plot of QR vs TIME, PARTICLE SIZE

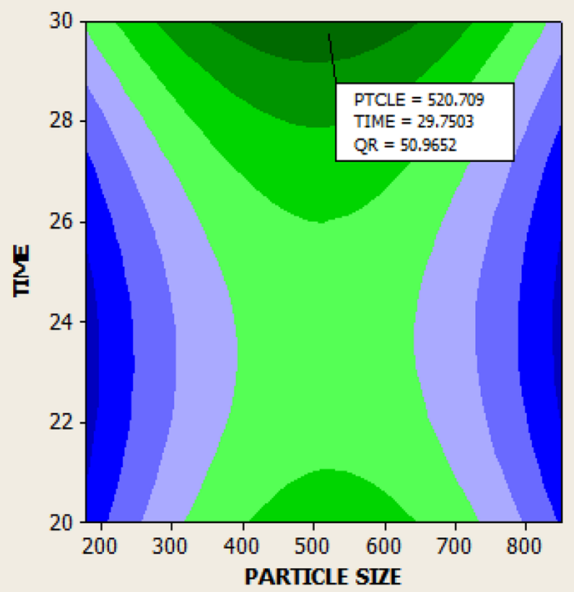

(b)

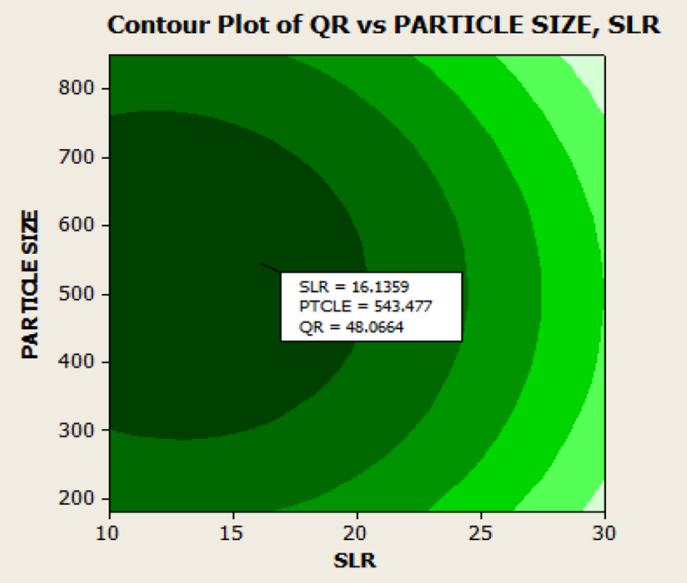

(c)

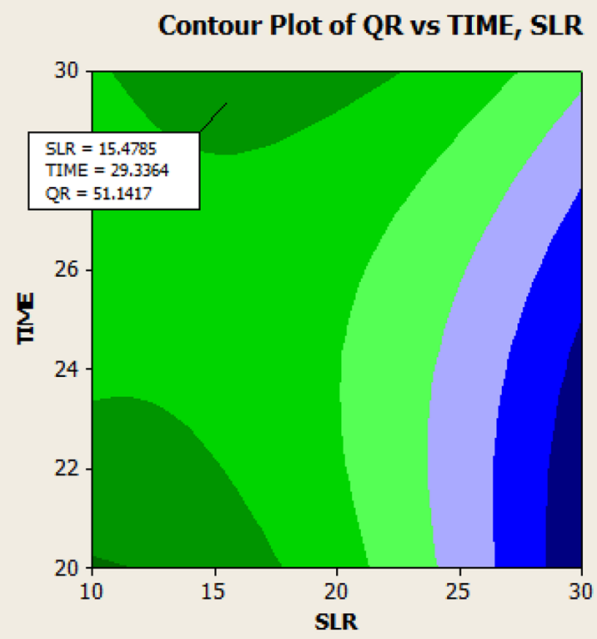

Surface Plot of QR vs TIME, PARTICLE SIZE

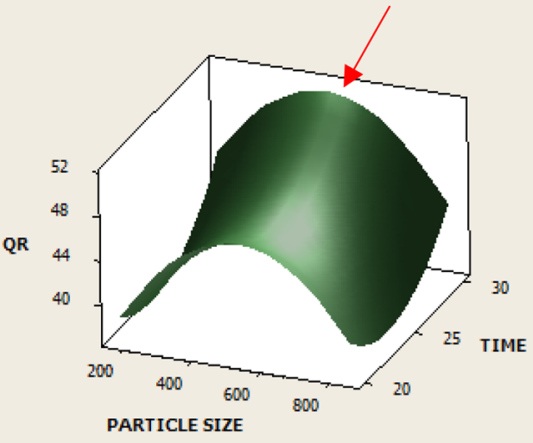

Surface Plot of QR vs PARTICLE SIZE, SLR

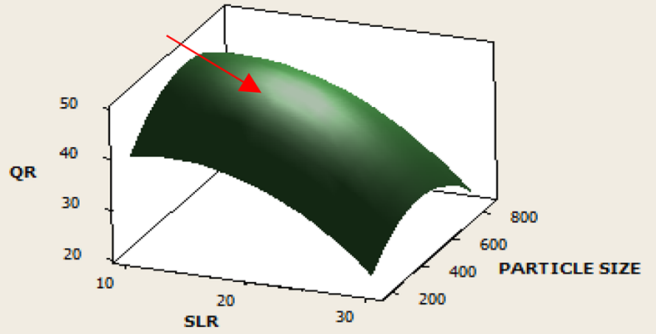

Surface Plot of QR vs TIME, SLR

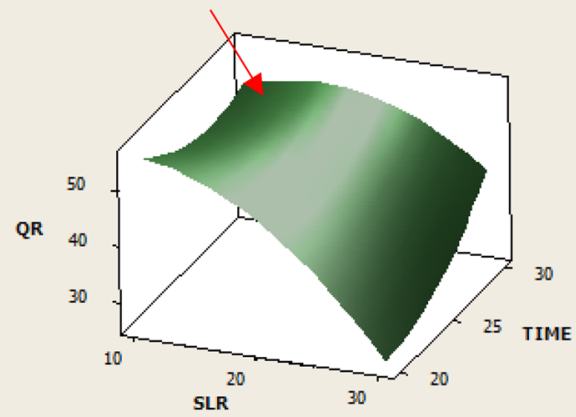

Figure 1. 2D contour plot (left) and 3D surface plot (right) showing the influence of time and particle size (a), time and SLR (b) and particle size and SLR (c) on quercitrin content. The line on surface plot demonstrating the predicted optimal point. 
(a)

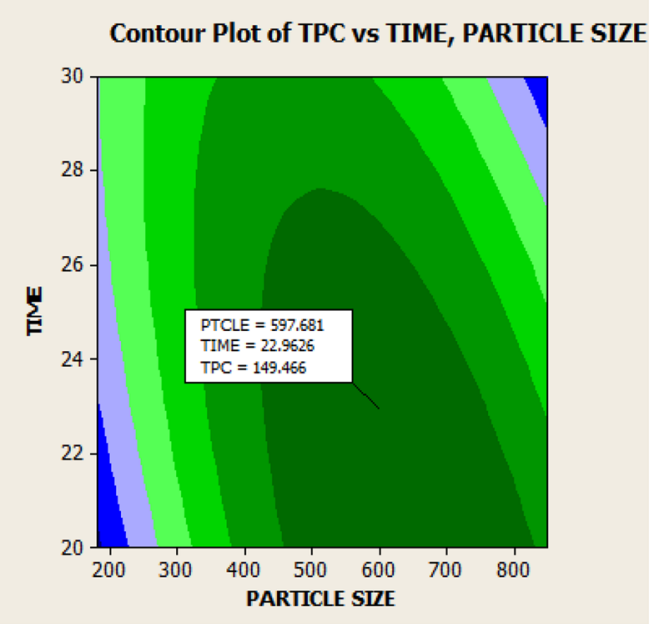

(b)

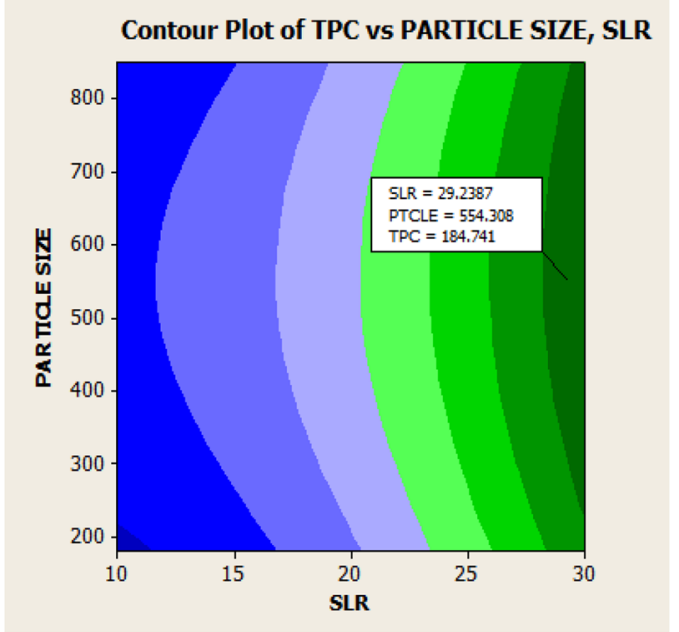

(c)
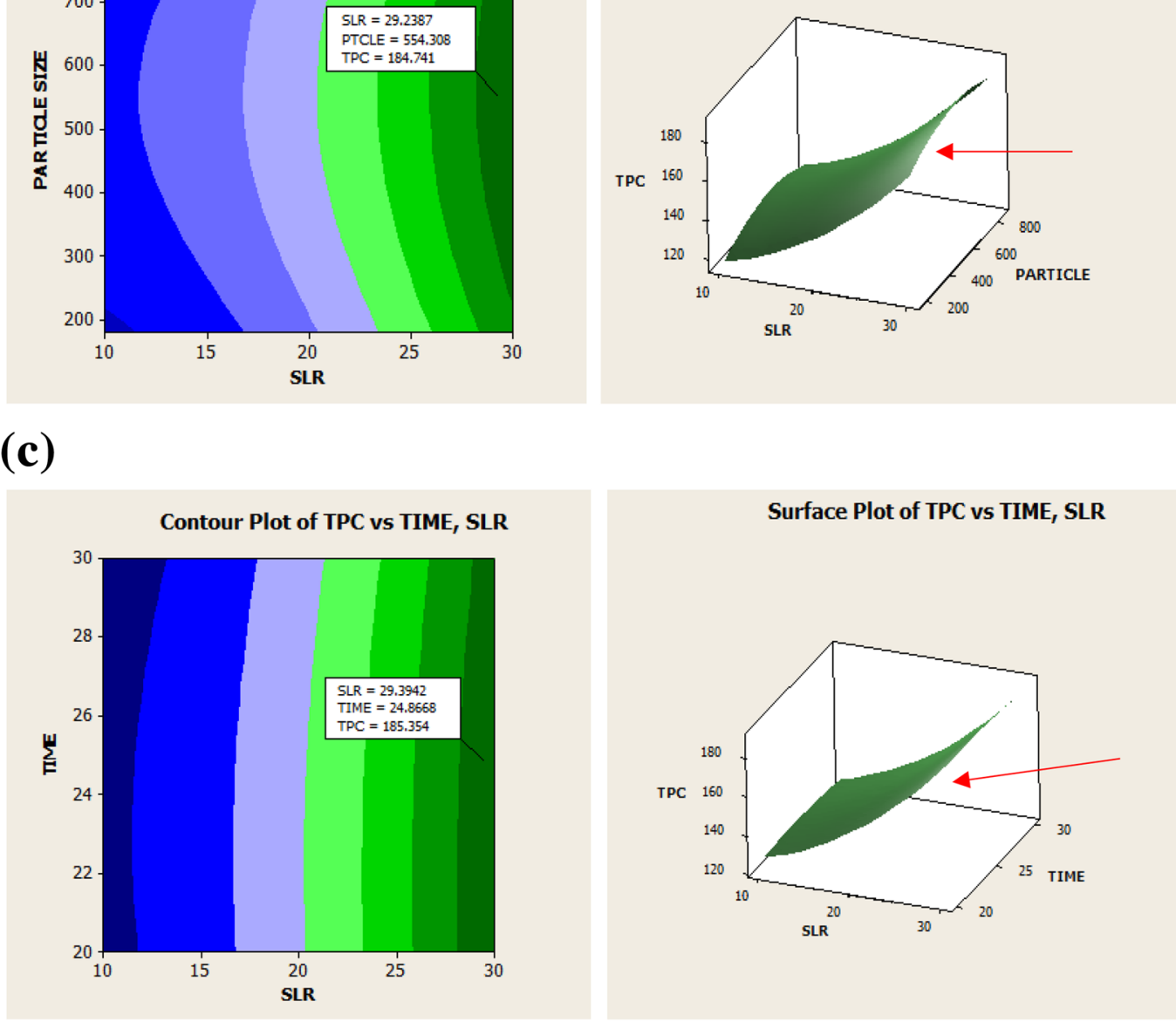

Figure 2. $2 \mathrm{D}$ contour plot (left) and $3 \mathrm{D}$ surface plot (right) showing the influence of time and particle size (a), time and SLR (b) and particle size and SLR (c), on TPC. The line on the surface plot demonstrating the predicted optimal point. 


\begin{tabular}{|l|l|l|l|}
\hline Responses & Experimental & Predicted & \% Error \\
\hline Quercitrin $(\mathrm{mg} / \mathrm{g} \mathrm{dw})$ & 42.57 & 44.26 & 3.81 \\
\hline Total TPC (mg GAE/g dw) & 169.75 & 175.64 & 3.72 \\
\hline
\end{tabular}

Table 4. Quercitrin and TPC yield under optimal ultrasonic extraction conditions.

\begin{tabular}{|l|l|l|l|}
\hline \multirow{2}{*}{ Method } & Extraction yield & TPC $(\mathbf{m g} / \mathbf{g ~ d w})$ & IC $_{50}(\mathbf{m g} / \mathbf{L})$ \\
\cline { 2 - 4 } & Quercitrin $(\mathbf{m g} / \mathbf{g ~ d w})$ & $125.97 \pm 1.64$ & $36.80 \pm 0.68$ \\
\hline Soxhlet & $35.50 \pm 0.24$ & $169.75 \pm 0.63$ & $20.83 \pm 1.33$ \\
\hline Ultrasonic & $42.57 \pm 0.51$ &
\end{tabular}

Table 5. Comparison of extraction yield between ultrasonic and Soxhlet extraction methods. Values are presented as mean $\pm \operatorname{SD}(n=3)$.

error between the predicted and experimental values was less than $4 \%$, which justifies an appropriate suitability. Through this validation study, the above-developed regression models were found to be suitable to optimise the ultrasonication process.

Comparison of ultrasonic extraction with Soxhlet. Extraction by ultrasonics is a novel extraction method with advantages such as higher extraction efficiency, lower solvent consumption, and shorter extraction time ${ }^{31,55}$. Many studies have been carried out in the literature to compare the influence of extraction methods on extraction yields, such as bioactive compounds, phenolic compounds, and antioxidant properties of various plant species ${ }^{56,57}$. Specifically, extraction via ultrasonic and microwave techniques has proved to be the most effective extraction method for a higher recovery of bioactive compounds from Panax ginseng and Gingko biloba $a^{56}$.

Quercitrin, TPC, and antioxidant property extracted using ultrasonics were found to be higher than Soxhlet extraction (Table 5). This proved that ultrasonic extraction has successfully enhanced the extraction yields from the plant extract. Seyedreihani et al. ${ }^{16}$, revealed that the TPC in the C. caudatus aqueous extract was $37.41 \mathrm{mg}$ GAE/g dw. TPC in the $80 \%$ ethanolic extract was $15.8 \mathrm{mg} \mathrm{GAE} / 100 \mathrm{~g} \mathrm{dw}^{13}$. Comparatively, the low value of TPC is due to the authors not performing optimization of the extraction parameters in their study. It is reported that the beneficial active compounds from the plant are mostly from the flavonoids derivatives ${ }^{9,16}$. Adarwulan et al. ${ }^{58}$ reported that the sum flavonoids compounds (consisting of quercetin, kaempferol, luteolin, apigenin) on a dry basis was $3.72 \mathrm{mg} / 100 \mathrm{~g}$. Compared with our result, quercitrin which is a major flavonoids constituent in the plant extract was 11 -fold higher than the reported sum flavonoids compound. Sharifuldin et al. ${ }^{14}$ had reported the average value of quercitrin in the $75 \%$ ethanolic extract using Soxhlet ranged from 8.13 to $11 \%$ (w/w, in $\mathrm{dw}$ ). Yusoff et al. ${ }^{9}$ had reported the concentration of quercitrin in the methanol was about $29.66 \mathrm{mg} / \mathrm{g} \mathrm{dw}$. While, in the study by Seyedreihani et al. ${ }^{16}$, the water extract contains $36.90 \mathrm{mg} / \mathrm{g}$ of quercitrin. The values reported of this major compound among the $C$. caudatus extracts differ due to several reasons such as maturity, treatment or environmental changes ${ }^{59}$. According to Mediani et al. ${ }^{13}$, quercitrin showed the highest concentration $(9.58 \mathrm{mg} / \mathrm{g})$ in the dry season and the 8 th-week development stage. In a previous study by Mohd Khairi et al..$^{32}$, the effect of different extraction methods on ascorbic acid content was compared between ultrasonic, maceration, and Soxhlet ${ }^{32}$. Their established results showed that the ultrasonic extraction method was most effective with $26.59 \mathrm{mg} / \mathrm{g} \mathrm{dw}$ ascorbic acid obtained from the plant extract. The antioxidant inhibition based on the $\mathrm{IC}_{50}$ of the extract in ultrasonic extraction and Soxhlet were $20.83 \pm 1.33 \mathrm{mg} / \mathrm{L}$ and $36.80 \pm 0.68 \mathrm{mg} / \mathrm{L}$, respectively. The results notably increased 0.57 -fold compared to the results produced by the Soxhlet method. Interestingly, this value is also close to the $\mathrm{IC}_{50}$ of the standard ascorbic acid value at $13.25 \pm 0.45 \mathrm{mg} / \mathrm{L}$. In summary, the results demonstrated that the extraction method plays an important role in recovering extraction yield.

Ultrasonic extraction was found to be a robust method for high yield of quercitrin, TPC, and antioxidant property from C. caudatus leaves extract. Nevertheless, the reduction in both extraction time and required solvent makes ultrasonic extraction more efficient than the Soxhlet method. The difference in results could be associated with the process of extraction involved.

Evaluation of the antimicrobial potential of $C$. caudatus extract. The antimicrobial potential of C. caudatus extract was determined against two human pathogenic bacteria, namely, Staphylococcus aureus $(S$. aureus) and Escherichia coli (E. coli). Results of the inhibition growth of these Gram-positive and Gram-negative bacteria present their apparent clear zone as shown in Table 6 . After incubation at $37^{\circ} \mathrm{C}$ for $24 \mathrm{~h}$, the inhibition growth of $S$. aureus had produced a clear zone of diameter $22.67 \pm 0.57 \mathrm{~mm}$, while E. coli had produced a clear zone of diameter $21.57 \pm 0.50 \mathrm{~mm}$ (Fig. 3). The inhibition zone of quercitrin was similar to the positive control, forming a clear zone of diameter $23.31 \pm 0.72 \mathrm{~mm}$ for $S$. aureus, and $22.86 \pm 0.31 \mathrm{~mm}$ for E. coli at the tested concentration $(1 \mathrm{mg} / \mathrm{mL})$. The finding proved that quercitrin, as an active plant compound in C. caudatus $80 \%$ ethanolic extract, is responsible for antimicrobial activity. A similar result was reported by Yusuff et al. ${ }^{9}$ who found the antimicrobial activity of C. caudatus leaves extract might be due to the presence of quercitrin. Besides, 


\begin{tabular}{|l|l|l|}
\hline \multirow{2}{*}{ Sample } & Zone of inhibition $(\mathbf{m m})$ & \\
\cline { 2 - 3 } C.caudatus extract & Staphylococcus aureus & Escherichia coli \\
\hline Quercitrin standard & $22.67 \pm 0.57$ & $21.57 \pm 0.50$ \\
\hline Streptomycin & $23.31 \pm 0.72$ & $22.86 \pm 0.31$ \\
\hline
\end{tabular}

Table 6. Antimicrobial activity of C. caudatus leaves extract.
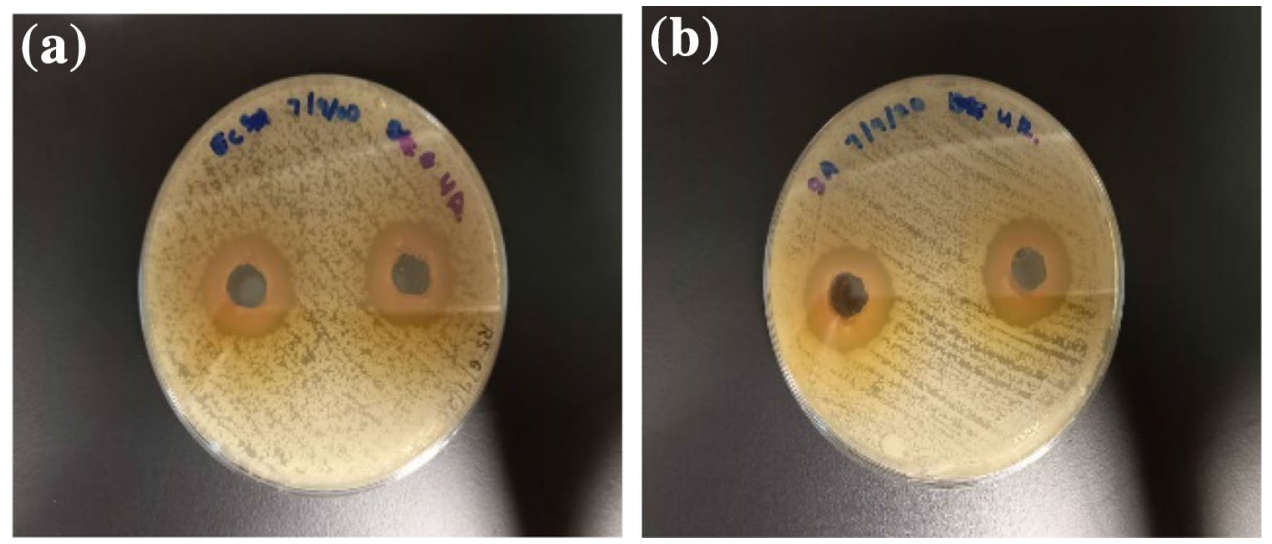

Figure 3. Inhibition zone of C. caudatus extract on (a) E. coli, (b) S. aureus.

quercetin and its derivatives produced an extraordinary effect of bacterial resistance against several human pathogenic bacteria such as Staphylococcus aureus, Staphylococcus epidermidis, Porphyromonas gingivalis, Bacillus subtilis, and Escherichia coli $i^{6-62}$. The results reveal the capabilities of the extract as an anti-microbial agent, similar to the previous studies ${ }^{7,8}$.

Identification of compounds of bioactive compounds by HPLC. The chromatographic profile of the sample extract identified three compounds, namely, quercitrin, quercetin glycoside, and rutin (Fig. 4). The major compound was identified as quercitrin, which was eluted at $6.73 \mathrm{~min}$. Quercetin glycoside and rutin were eluted at $6.34 \mathrm{~min}$ and $5.08 \mathrm{~min}$, respectively. This HPLC chromatogram profile were similar to the chromatogram profiles of Mediani et al. ${ }^{13}$, Sharifuldin et al. ${ }^{14}$ and Seyedreihani et al. ${ }^{16}$ in their sample extracts. However, the elution time of our compounds was much faster. The previous articles have reported that quercitrin was eluted at $19.93 \mathrm{~min}$ and $28.64 \mathrm{~min}^{12,15}$. The use of $0.3 \%$ formic acid and acetonitrile as mobile phases (and considered a suitable developed gradient system) has led to the rapid compound elution and is useful for the quantification of quercitrin in the sample extract. There was also one unidentified peak detected at $5.74 \mathrm{~min}$. The unknown peak may possibly be another phenolic compound or other flavonoids. This compound was also important and needed to be further identified as its presence constitutes the second largest peak in the samples. Further work is recommended to identify this unknown compound by using a more sophisticated analytical technique, such as HPLC mass spectrometry.

\section{Conclusions}

This study is perhaps the first to report on the use of the ultrasonic extraction method for the extraction and separation of quercitrin and TPC from C. caudatus leaves. According to the results, the optimum yield of quercitrin and TPC were $42.57 \mathrm{mg} / \mathrm{g}$ and $169.75 \mathrm{mg}$ GAE/g respectively. The optimum extraction variables involved using a SLR of 1:28 (g/mL), particle size of $485 \mu \mathrm{m}$ and extraction time of $30 \mathrm{~min}$. The ultrasonic extraction method has been proven to increase the yield of the extracted components and to have additional advantages such as shorter time, lower solvent amount, and low operational cost over the Soxhlet extraction method. The results demonstrated the capabilities of the extract as an antimicrobial agent. This developed ultrasonic extraction method can contribute to the development of extraction protocols, or for further fractionation of bioactive compounds from C. caudatus leaves or other medicinal plants.

\section{Data availability}

The datasets generated or analysed during this study are included in this article. 


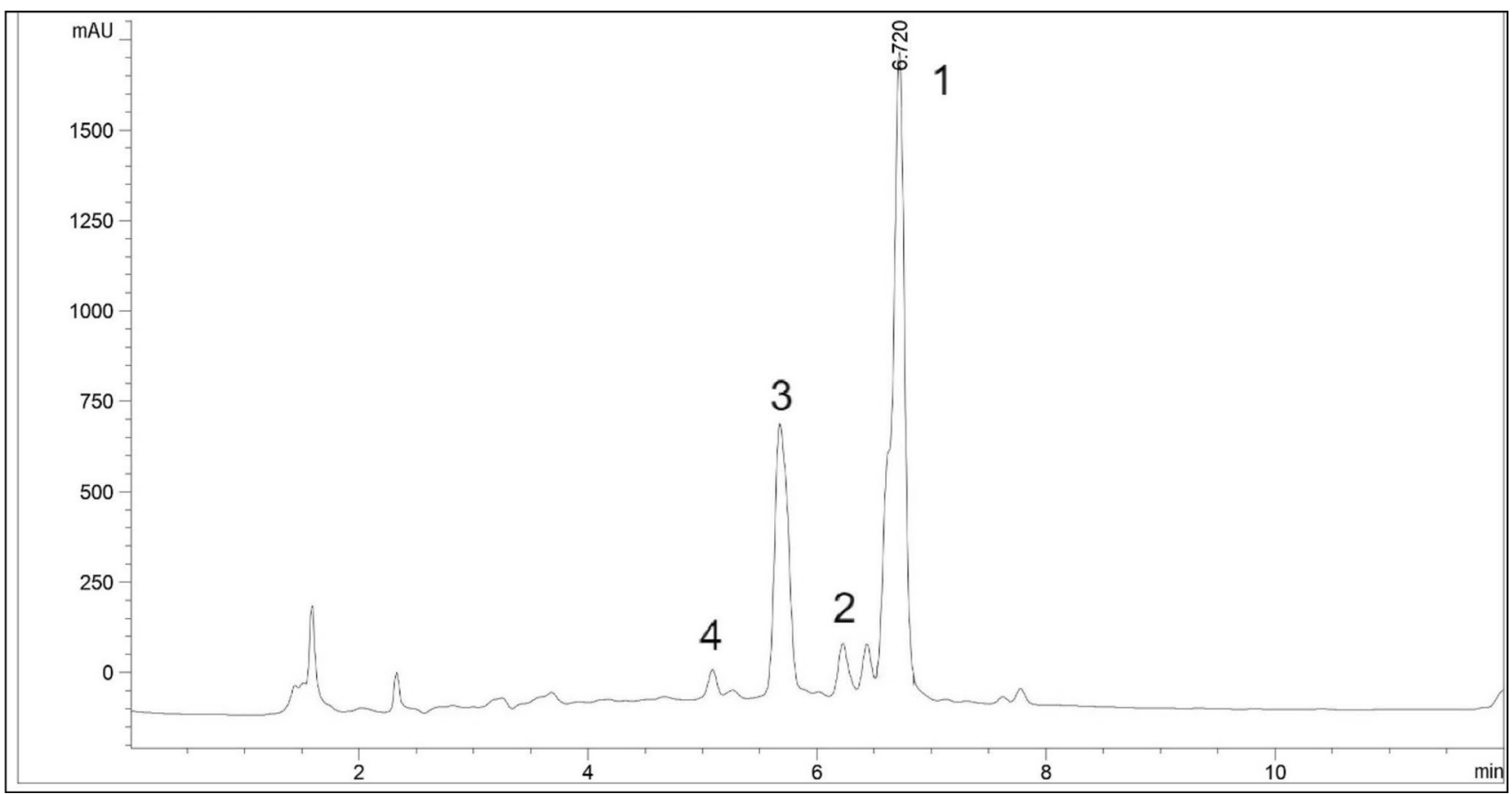

Figure 4. HPLC chromatogram of C. caudatus extract at $260 \mathrm{~nm}$. The peak as follow: 1, quercitrin; 2 quercetin glycoside; 3 , unknown peak; 4 , rutin.

Received: 8 January 2021; Accepted: 10 August 2021

Published online: 27 August 2021

\section{References}

1. Cheng, S. H., Yusof, B. N. M., Hamid, A. \& Ismail, A. The King of Salad, Ulam raja (Cosmos caudatus) in Functional Food: Wonder of the World (UPM Press, 2017).

2. Moshawih, S., Cheeme, M. S., Ahmad, Z., Zakaria, Z. A. \& Hakim, M. N. A comprehensive review on Cosmos caudatus (Ulam Raja): Pharmacology, ethnopharmacology, and phytochemistry. Int. Res. J. Educ. Sci. https://doi.org/10.1007/s00170-013-4743-1 (2017).

3. Chiang Chan, E. W. et al. Antioxidant properties of selected fresh and processed herbs and vegetables. Free Radic. Antioxid. https:// doi.org/10.5530/fra.2014.1.7 (2014).

4. Uzbek, U. H. \& Shahidan, W. N. S. Tasty herb that heals: A review of Cosmos caudatus (Ulam raja) and its potential uses in dentistry. World J. Dent. 10, 321-324 (2019).

5. Abdul Rahman, H. et al. Anti-obesity and antioxidant activities of selected medicinal plants and phytochemical profiling of bioactive compounds. Int. J. Food Prop. https://doi.org/10.1080/10942912.2016.1247098 (2017).

6. Amalia, L., Anggadiredja, K., Sukrasno, F. I. \& Inggriani, R. Antihypertensive potency of wild cosmos (Cosmos caudatus Kunth, Asteraceae) leaf extract. J. Pharmacol. Toxicol. https://doi.org/10.3923/jpt.2012.359.368 (2012).

7. Hafipah, N., Rasdi, M., Samah, O. A., Sule, A. \& Ahmed, Q. U. Antimicrobial studies of Cosmos caudatus Kunth. (Compositae). J. Med. Plants Res. https://doi.org/10.5897/JMPR09.422 (2010).

8. Yusoff, N. A. H., Bustaman, M. S., Abas, F., Khatib, A. \& Rukayadi, Y. Antimicrobial activity of Cosmos caudatus extract against foodborne pathogens. J. Pure Appl. Microbiol. (2014).

9. Yusoff, N. A. H., Rukayadi, Y., Abas, F., Khatib, A. \& Hassan, M. Antimicrobial stability of Cosmos caudatus extract at varies $\mathrm{pH}$ and temperature, and compounds identification for application as food sanitiser. Food Res. 5, 83-91 (2021).

10. Wong, S. P., Leong, L. P. \& William Koh, J. H. Antioxidant activities of aqueous extracts of selected plants. Food Chem. 99, 775-783 (2006)

11. Mustafa, R. A., Hamid, A. A., Mohamed, S. \& Bakar, F. A. Total phenolic compounds, flavonoids, and radical scavenging activity of 21 selected tropical plants. J. Food Sci. https://doi.org/10.1111/j.1750-3841.2009.01401.x (2010).

12. Cheng, S. H., Barakatun-Nisak, M. Y., Anthony, J. \& Ismail, A. Potential medicinal benefits of Cosmos caudatus (Ulam Raja): A scoping review. J. Res. Med. Sci. https://doi.org/10.4103/1735-1995.172796 (2015).

13. Mediani, A., Abas, F., Khatib, A. \& Tan, C. P. Cosmos Caudatus as a potential source of polyphenolic compounds: Optimisation of oven drying conditions and characterisation of its functional properties. Molecules 18, 10452-10464 (2013).

14. Sharifuldin, M. M. A., Ismail, Z., Aisha, A. F. A., Seow, E. K. \& Beh, H. K. Quantification of rutin, quercitrin and quercetin in Cosmos caudatus Kunth by reverse phase high performance liquid chromatography. Qual. Assur. Saf. Crop Foods https://doi.org/ 10.3920/QAS2015.0839 (2016)

15. Shui, G., Leong, L. P. \& Shih, P. W. Rapid screening and characterisation of antioxidants of Cosmos caudatus using liquid chromatography coupled with mass spectrometry. J. Chromatogr. B Anal. Technol. Biomed. Life Sci. 827, 127-138 (2005).

16. Seyedreihani, S. F., Tan, T. C., Alkarkhi, A. F. M. \& Easa, A. M. Total phenolic content and antioxidant activity of Ulam raja (Cosmos caudatus) and quantification of its selected marker compounds: Effect of extraction. Int. J. Food Prop. 20, 260-270 (2017).

17. Li, X., Jiang, Q., Wang, T., Liu, J. \& Chen, D. Comparison of the antioxidant effects of quercitrin and isoquercitrin: Understanding the role of the 6"-OH group. Molecules 21, 1246 (2016).

18. Soberón, J. R., Sgariglia, M. A., Sampietro, D. A., Quiroga, E. N. \& Vattuone, M. A. Antibacterial activity of plant extracts from northwestern Argentina. J. Appl. Microbiol. 102, 1450-1461 (2007).

19. Cruz, E. A. et al. International immunopharmacology immunomodulatory pretreatment with Kalanchoe pinnata extract and its quercitrin flavonoid effectively protects mice against fatal anaphylactic shock. Int. Immunopharmacol. 8, 1616-1621 (2008). 
20. Satué, M., Arriero, M. D. M., Monjo, M. \& Ramis, J. M. Quercitrin and Taxifolin stimulate osteoblast differentiation in MC3T3-E1 cells and inhibit osteoclastogenesis in RAW 264.7 cells. Biochem. Pharmacol. 86, 1476-1486 (2013).

21. Azmin, S. N. H. M. et al. Herbal processing and extraction technologies. Sep. Purif. Rev. 45, 305-320 (2016).

22. Mahdi, A. A. et al. Enhancing bio-recovery of bioactive compounds extracted from Citrus medica L. Var. sarcodactylis: Optimization performance of integrated of pulsed-ultrasonic/microwave technique. J. Food Meas. Charact. 13, 1661-1673 (2019).

23. Chemat, F. et al. Review of green food processing techniques. Preservation, transformation, and extraction. Innov. Food Sci. Emerg. Technol. 41, 357-377 (2017).

24. Chemat, F., Vian, M. A. \& Cravotto, G. Green extraction of natural products: Concept and principles. Int. J. Mol. Sci. 13, 8615-8627 (2012).

25. Pradal, D., Vauchel, P., Decossin, S., Dhulster, P. \& Dimitrov, K. Kinetics of ultrasound-assisted extraction of antioxidant polyphenols from food by-products: Extraction and energy consumption optimization. Ultrason. Sonochem. 32, 137-146 (2016).

26. Da Porto, C. \& Natolino, A. Extraction kinetic modelling of total polyphenols and total anthocyanins from saffron floral bioresidues: Comparison of extraction methods. Food Chem. 258, 137-143 (2018).

27. Dumitraşcu, L., Enachi, E., Stănciuc, N. \& Aprodu, I. Optimization of ultrasound assisted extraction of phenolic compounds from cornelian cherry fruits using response surface methodology. CYTA J. Food 17, 814-823 (2019).

28. Dranca, F. \& Oroian, M. Optimization of ultrasound-assisted extraction of total monomeric anthocyanin (TMA) and total phenolic content (TPC) from eggplant (Solanum melongena L.) peel. Ultrason. Sonochem. 31, 637-646 (2016).

29. Umaña, M., Eim, V., Garau, C., Rosselló, C. \& Simal, S. Ultrasound-assisted extraction of ergosterol and antioxidant components from mushroom by-products and the attainment of a $\beta$-glucan rich residue. Food Chem. 332, 127390 (2020).

30. Wen, C. et al. Advances in ultrasound assisted extraction of bioactive compounds from cash crops-A review. Ultrason. Sonochem. https://doi.org/10.1016/j.ultsonch.2018.07.018 (2018).

31. Chemat, F. et al. Ultrasound assisted extraction of food and natural products. Mechanisms, techniques, combinations, protocols and applications. A review. Ultrason. Sonochem. 34, 540-560 (2017).

32. Mohd Khairi, N. A. Antioxidant activity of Cosmos caudatus extracts by using different types of extraction methods. J. Chem. Inf. Model. https://doi.org/10.1017/CBO9781107415324.004 (2013).

33. Mohd Nasir, B. The Effect of Extraction Parameters on Antioxidant Activity of Cosmos caudatus (Universiti Malaysia Pahang, 2011).

34. Cheng, S. H., Khoo, H. E., Ismail, A., Abdul-Hamid, A. \& Barakatun-Nisak, M. Y. Influence of extraction solvents on Cosmos caudatus leaf antioxidant properties. Iran. J. Sci. Technol. Trans. Sci. https://doi.org/10.1007/s40995-016-0007-x (2016).

35. Zulkiply, H. Optimization of Extraction Parameteres of Total Phenolic Compound from Cosmos caudatus (Universiti Malaysia Pahang, 2012).

36. Safdar, M. N. et al. Extraction and quantification of polyphenols from kinnow (Citrus reticulate L.) peel using ultrasound and maceration techniques. J. Food Drug Anal. 25, 488-500 (2017).

37. Latiff, N. A., Abdullah, L. C., Ong, P. Y., Embi, K. \& Malek, S. A. The influence of drying temperature on the quality, morphology and drying characteristics of Cosmos caudatus. IOP Conf. Ser. Mater. Sci. Eng. 991, 10-18 (2020).

38. Ramadhan, F. et al. Flavonoids from endophytic bacteria of Cosmos caudatus Kunth. Leaf as anticancer and antimicrobial. Asian J. Pharm. Clin. Res. 11, 200-204 (2018).

39. Mohd, A. A. Optimization and Fractionation of Quercitrin-Rich Extract from Melastoma Malabthricum Leves and Its Bioactivities (Universti Teknologi Malaysia, 2019).

40. Ma, F., Zhao, Y., Gong, X., Xie, Y. \& Zhou, X. Optimization of quercitrin and total flavonoids extraction from Herba Polygoni Capitati by response surface methodology. Pharmacogn. Mag. 10, S57-S64 (2014).

41. Pandey, A., Belwal, T., Sekar, K. C., Bhatt, I. D. \& Rawal, R. S. Optimization of ultrasonic-assisted extraction (UAE) of phenolics and antioxidant compounds from rhizomes of Rheum moorcroftianum using response surface methodology (RSM). Ind. Crops Prod. 119, 218-225 (2018).

42. Chen, S. et al. Simultaneous optimization of the ultrasound-assisted extraction for phenolic compounds content and antioxidant activity of Lycium ruthenicum Murr. fruit using response surface methodology. Food Chem. 242, 1-8 (2018).

43. Asfaram, A., Ghaedi, M., Hajati, S. \& Goudarzi, A. Synthesis of magnetic $\gamma$ - $\mathrm{Fe}_{2} \mathrm{O}_{3}$-based nanomaterial for ultrasonic assisted dyes adsorption: Modeling and optimization. Ultrason. Sonochem. https://doi.org/10.1016/j.ultsonch.2016.04.011 (2016).

44. Mojerlou, Z. \& Elhamirad, A. Optimization of ultrasound-assisted extraction (UAE) of phenolic compounds from olive cake. J. Food Sci. Technol. 55, 977-984 (2018).

45. Oroian, M., Ursachi, F. \& Dranca, F. Influence of ultrasonic amplitude, temperature, time and solvent concentration on bioactive compounds extraction from propolis. Ultrason. Sonochem. https://doi.org/10.1016/j.ultsonch.2020.105021 (2020).

46. Rajković, K. M. et al. Optimization of extraction yield and chemical characterization of optimal extract from Juglans nigra L. leaves. Chem. Eng. Res. Des. 157, 25-33 (2020).

47. Arteaga-Crespo, Y., Radice, M., Bravo-Sanchez, L. R., García-Quintana, Y. \& Scalvenzi, L. Optimisation of ultrasound-assisted extraction of phenolic antioxidants from Ilex guayusa Loes. leaves using response surface methodology. Heliyon 6, 1-7 (2020).

48. Jahongir, H., Miansong, Z., Amankeldi, I., Yu, Z. \& Changheng, L. The influence of particle size on supercritical extraction of dog rose (Rosa canina) seed oil. J. King Saud Univ. Eng. Sci. 31, 140-143 (2019).

49. de Melo, M. M. R. et al. Supercritical $\mathrm{CO}_{2}$ extraction of V. vinifera leaves: Influence of cosolvents and particle size on removal kinetics and selectivity to target compounds. J. Supercrit. Fluids 165, 104959 (2020).

50. He, B. et al. Optimization of ultrasound-assisted extraction of phenolic compounds and anthocyanins from blueberry (Vaccinium ashei) wine pomace. Food Chem. https://doi.org/10.1016/j.foodchem.2016.02.094 (2016).

51. Vuong, Q. V., Golding, J. B., Stathopoulos, C. E., Nguyen, M. H. \& Roach, P. D. Optimizing conditions for the extraction of catechins from green tea using hot water. J. Sep. Sci. 34, 3099-3106 (2011).

52. Chen, F., Zhang, Q., Fei, S., Gu, H. \& Yang, L. Optimization of ultrasonic circulating extraction of samara oil from Acer saccharum using combination of Plackett-Burman design and Box-Behnken design. Ultrason. Sonochem. 35, 161-175 (2017).

53. Backes, E. et al. Recovery of bioactive anthocyanin pigments from Ficus carica L. peel by heat, microwave, and ultrasound based extraction techniques. Food Res. Int. https://doi.org/10.1016/j.foodres.2018.07.016 (2018).

54. Kumar, K., Srivastav, S. \& Sharanagat, V. S. Ultrasound assisted extraction (UAE) of bioactive compounds from fruit and vegetable processing by-products: A review. Ultrason. Sonochem. 70, 105325 (2021).

55. Saifullah, M., McCullum, R., McCluskey, A. \& Vuong, Q. Comparison of conventional extraction technique with ultrasound assisted extraction on recovery of phenolic compounds from lemon scented tea tree (Leptospermum petersonii) leaves. Heliyon $\mathbf{6}$, e03666 (2020).

56. Tsaltaki, C., Katsouli, M., Kekes, T., Chanioti, S. \& Tzia, C. Comparison study for the recovery of bioactive compounds from Tribulus terrestris, Panax ginseng, Gingko biloba, Lepidium meyenii, Turnera diffusa and Withania somnifera by using microwaveassisted, ultrasound-assisted and conventional extraction methods. Ind. Crops Prod. 142, 111875 (2019).

57. López, C. J. et al. Optimization and comparison of heat and ultrasound assisted extraction techniques to obtain anthocyanin compounds from Arbutus unedo L. Fruits. Food Chem. 264, 81-91 (2018).

58. Andarwulan, N., Batari, R., Sandrasari, D. A., Bolling, B. \& Wijaya, H. Flavonoid content and antioxidant activity of vegetables from Indonesia. Food Chem. 121, 1231-1235 (2010).

59. Shuib, N. H. et al. Discrimination of young and mature leaves of Melicope ptelefolia using 1H NMR and multivariate data analysis. Food Chem. 126, 640-645 (2011). 
60. Siriwong, S., Teethaisong, Y., Thumanu, K., Dunkhunthod, B. \& Eumkeb, G. The synergy and mode of action of quercetin plus amoxicillin against amoxicillin-resistant Staphylococcus epidermidis. BMC Pharmacol. Toxicol. 17, 1-14 (2016).

61. Aderogba, M. A., Ndhlala, A. R., Rengasamy, K. R. R. \& Van Staden, J. Antimicrobial and selected in vitro enzyme inhibitory effects of leaf extracts, flavonols and indole alkaloids isolated from Croton menyharthii. Molecules 18, 12633-12644 (2013).

62. Geoghegan, F., Wong, R. W. K. \& Rabie, A. B. M. Inhibition of cholinesterase and amyloid-\&bgr; aggregation by resveratrol oligomers from Vitis amurensis. Phyther. Res. 22, 544-549 (2008).

63. Farhadi, F., Khameneh, B., Iranshahi, M. \& Iranshahy, M. Antibacterial activity of flavonoids and their structure-activity relationship: An update review. Phyther. Res. 33, 13-40 (2019).

\section{Acknowledgements}

Authors acknowledge to the technical research support team from Innovation Centre in Agritechnology, Universiti Teknologi Malaysia; Salimah Ab. Malek (HPLC analysis), Mohd Nadzreen Hidayat Sarjuni (sample harvested and collection) and Nur Hidayah Shadan (antimicrobial analysis).

\section{Author contributions:}

Conceptualization and supervision, L.C.A., and P.Y.O.; Methodology, software and validation, N.A.L., and P.Y.O.; Original draft preparation N.A.L.; Editing and Review draft, S.N.A.A.R., and P.Y.O., Review of the final Draft, L.C.A., P.Y.O., N.A.M.A, and N.A.M.F.; Funding acquisition, L.C.A. All authors have read and agreed to the published version of the manuscript.

\section{Competing interests}

The authors declare no competing interests.

\section{Additional information}

Supplementary Information The online version contains supplementary material available at https://doi.org/ 10.1038/s41598-021-96623-x.

Correspondence and requests for materials should be addressed to N.A.L. or L.C.A.

Reprints and permissions information is available at www.nature.com/reprints.

Publisher's note Springer Nature remains neutral with regard to jurisdictional claims in published maps and institutional affiliations.

(c) (i) Open Access This article is licensed under a Creative Commons Attribution 4.0 International License, which permits use, sharing, adaptation, distribution and reproduction in any medium or format, as long as you give appropriate credit to the original author(s) and the source, provide a link to the Creative Commons licence, and indicate if changes were made. The images or other third party material in this article are included in the article's Creative Commons licence, unless indicated otherwise in a credit line to the material. If material is not included in the article's Creative Commons licence and your intended use is not permitted by statutory regulation or exceeds the permitted use, you will need to obtain permission directly from the copyright holder. To view a copy of this licence, visit http://creativecommons.org/licenses/by/4.0/.

(C) The Author(s) 2021 